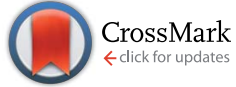

Cite this: RSC Adv., 2017, 7, 3439

Received 24th November 2016 Accepted 12th December 2016

DOI: $10.1039 / c 6 r a 27292 d$

\section{A facilely synthesized lactam acceptor unit for high-performance polymer donors $\uparrow$}

\author{
Han Pan,,$^{\mathrm{ab}}$ Zuo Xiao, $\stackrel{+}{\mathrm{b}}^{\mathrm{b}}$ Fangyuan Xie, ${ }^{\mathrm{b}}$ Qifang Li ${ }^{\star a}$ and Liming Ding ${ }^{\star b}$
}

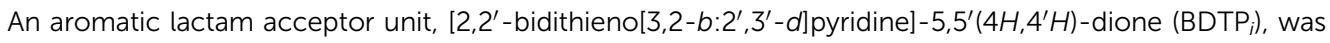
developed for making D-A copolymer donors. Two D-A copolymers, PThBDTP $i$ and PSeBDTP $i$, gave power conversion efficiencies (PCEs) of $8.11 \%$ and $6.50 \%$, respectively, when using $\mathrm{PC}_{71} \mathrm{BM}$ as the acceptor.

www.rsc.org/advances

Polymer solar cells (PSCs) have attracted great interests due to the advantages of lightweight, flexibility and roll-to-roll fabrication. ${ }^{1}$ The power conversion efficiencies (PCEs) for singlejunction PSCs have exceeded $12 \% .^{2}$ Developing donoracceptor (D-A) copolymer donors is an effective way to obtain efficient solar cells. ${ }^{3}$ Polycyclic aromatic building blocks are favorable for constructing high-performance D-A copolymers since the extended $\pi$-conjugation of these units can improve the light-harvesting capability and the hole mobility of the mate-

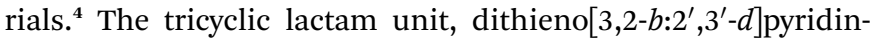
$5(4 H)$-one (DTP), has emerged as a promising acceptor unit for D-A copolymers. Yu et al. reported the first DTP copolymer, which gave a PCE of 5.33\%. ${ }^{5}$ By copolymerizing DTP with BDTT and IDT units, Yang et al. obtained wide-bandgap D-A copolymers, which afforded PCEs of $6.84 \%$ and $7.33 \%$, respectively. ${ }^{6}$ By linking two DTPs via "C7" position, we obtained a lactam unit, BDTP (Fig. 1). The BDTP-based D-A copolymers gave decent PCEs up to $9.13 \% .^{7}$ These results demonstrated the potential of DTP copolymers. Developing new DTP-based D-A copolymers is highly desirable. Here, we report a new lactam acceptor unit, BDTP $_{i}$, by linking two DTPs via "C2" position (Fig. 1). Different from the tedious synthesis of BDTP (8 steps from commercially available starting compounds), the synthesis of $\mathrm{BDTP}_{i}$ is simplified (only 4 steps from starting compounds). Two BDTP $_{i}$-based copolymers, PThBDTP $_{i}$ and $\operatorname{PSeBDTP}_{i}$, were prepared and used as the donor materials for PSCs. PThBDTP ${ }_{i}: \mathrm{PC}_{71} \mathrm{BM}$ solar cells gave a decent PCE of $8.11 \%$.

The synthetic routes for $\mathrm{BDTP}_{i}$ monomer and the copolymers are shown in Scheme 1. DTP was prepared according to

${ }^{a}$ State Key Laboratory of Chemical Resource Engineering, College of Materials Science and Engineering, Beijing University of Chemical Technology, Beijing 100029, China. E-mail: qflee@mail.buct.edu.cn

${ }^{b}$ CAS Center for Excellence in Nanoscience, CAS Key Laboratory of Nanosystem and Hierarchical Fabrication, National Center for Nanoscience and Technology, Beijing 100190, China.E-mail: ding@nanoctr.cn

$\dagger$ Electronic supplementary information (ESI) available: Materials preparation and characterization, solar cell fabrication and measurements. See DOI: 10.1039/c6ra27292d

‡. Pan and Z. Xiao contributed equally to this work. literature. ${ }^{6}$ The mono-bromination of DTP by NBS took place at "C7" rather than "C2", producing DTP-Br in $85 \%$ yield. The high regioselectivity was confirmed by heteronuclear multiple bond correlation (HMBC) spectrum of DTP-Br (Fig. S3†). The proton near bromine (7.63 ppm peak) correlates with the carbonyl carbon (157.57 ppm peak), thus ruling out "C2" bromination. The regioselective bromination implies that " $\mathrm{C} 7$ " presents higher electron density. The resonance structure of DTP could make "C7" to possess negative charge. A Pdcatalyzed dehydrogenative dimerization linked two DTP-Br via "C2", producing $\mathrm{BDTP}_{i}$ monomer in $31 \%$ yield. ${ }^{8}$ Finally, the copolymerization of $\mathrm{BDTP}_{i}$ monomer with 2,5-bis(trimethylstannyl)thiophene or 2,5-bis(trimethylstannyl)selenophene via Stille coupling gave PThBDTP or PSeBDTP $_{i}$ in 97\% and $88 \%$ yield, respectively. The number-average molecular weights $\left(M_{\mathrm{n}}\right)$ for PThBDTP $_{i}$ and PSeBDTP ${ }_{i}$ are $46.3 \mathrm{kDa}$ and 56.7 $\mathrm{kDa}$, with PDI of 2.07 and 1.74 , respectively. The decomposition temperature $\left(T_{\mathrm{d}}, 5 \% \mathrm{wt}\right.$ loss) for $\mathrm{PThBDTP}_{i}$ and $\mathrm{PSeBDTP}_{i}$ are $405{ }^{\circ} \mathrm{C}$ and $424{ }^{\circ} \mathrm{C}$, respectively, indicating their good thermal stability.

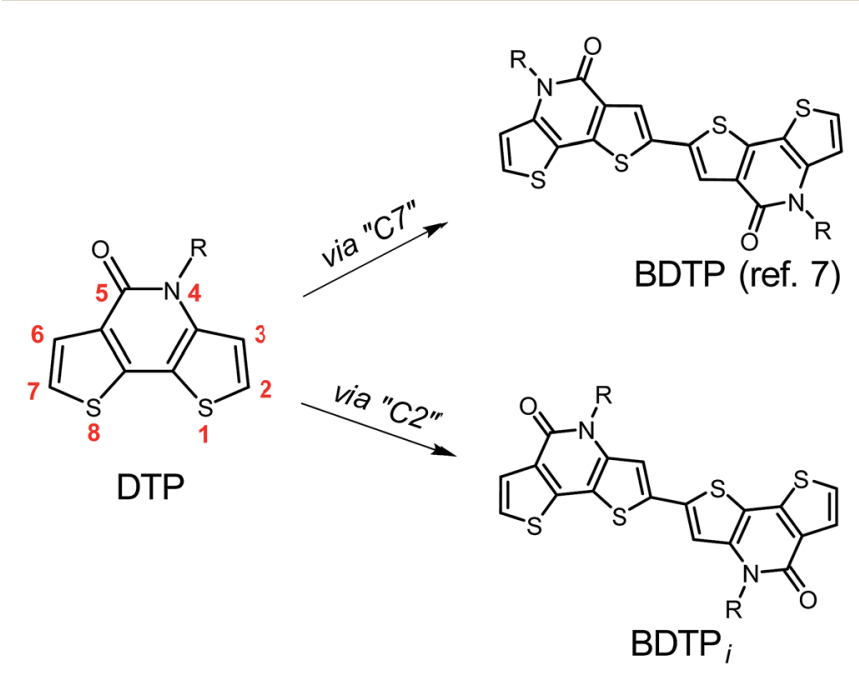

Fig. 1 Chemical structures for DTP, BDTP and BDTP ${ }_{i}$ 

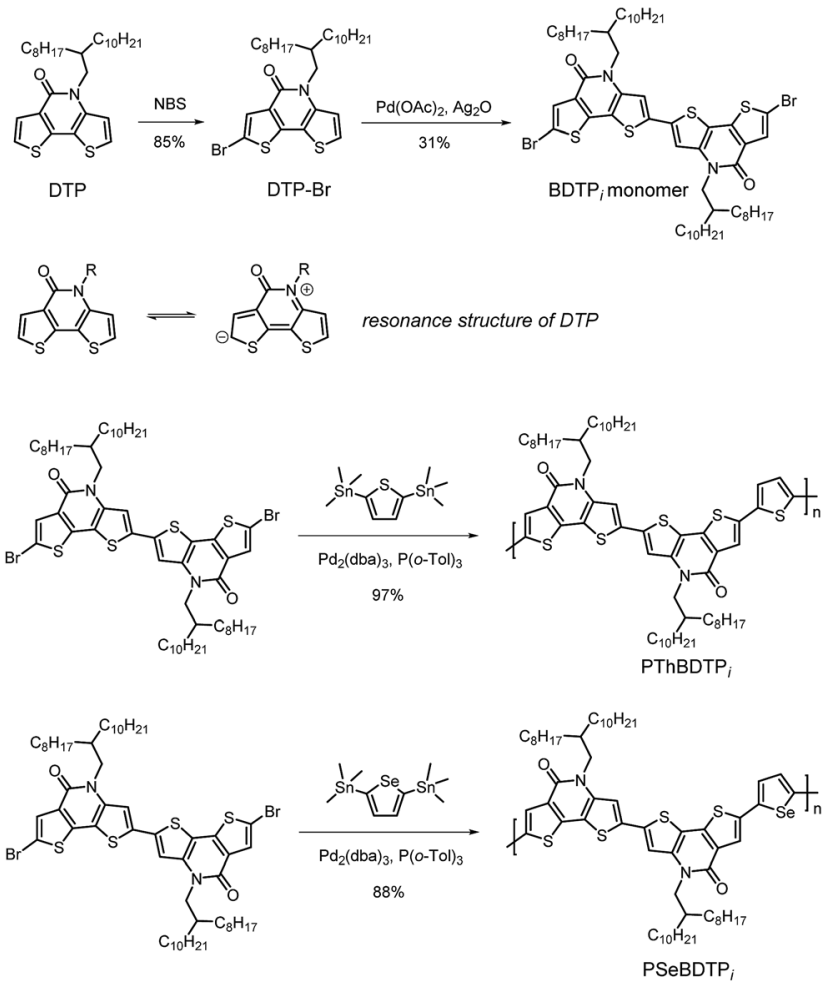

Scheme 1 Synthetic routes for BDTP ${ }_{i}$ monomer and the copolymers

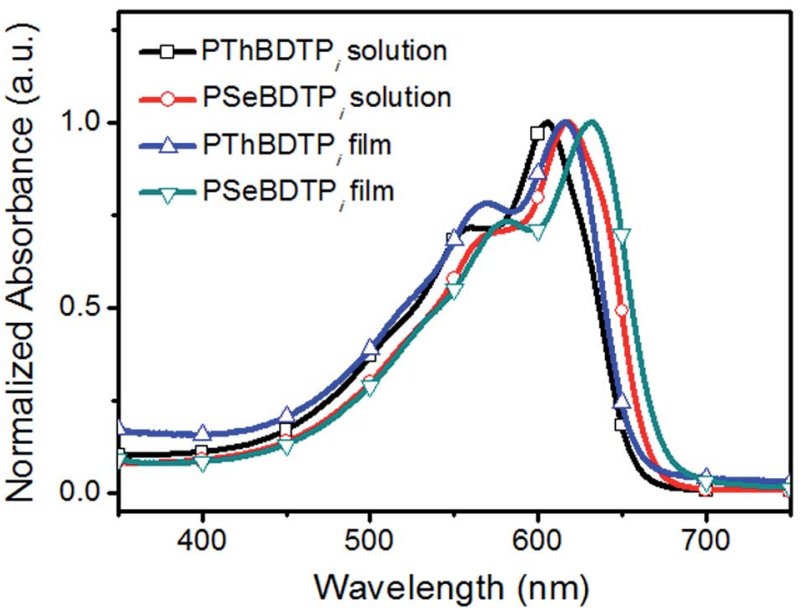

Fig. 2 Absorption spectra for PThBDTP $_{i}$ and PSeBDTP in solution and as films.

The absorption spectra for $\mathrm{PThBDTP}_{i}$ and $\mathrm{PSeBDTP}_{i}$ in solution and as films are shown in Fig. 2 and the optical data are listed in Table 1. In solution, $\operatorname{PThBDTP}_{i}$ and $\operatorname{PSeBDTP}_{i}$ show absorption
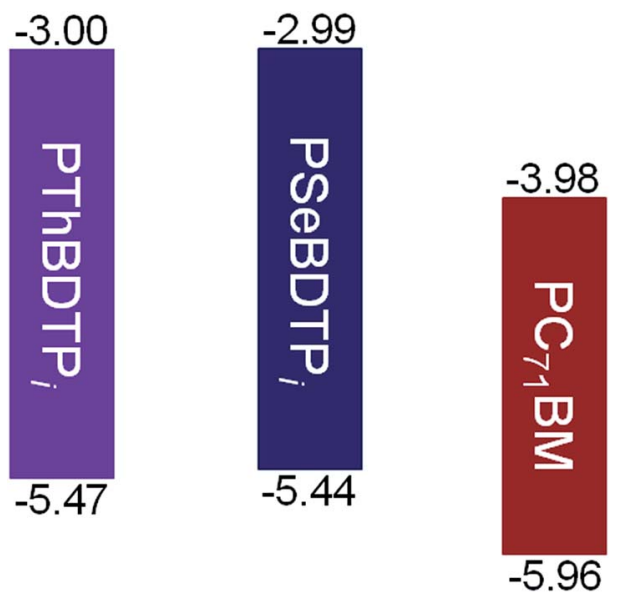

Fig. 3 The energy level diagram for $\mathrm{PThBDTP}_{i}, \mathrm{PSeBDTP}_{i}$ and $\mathrm{PC}_{71} \mathrm{BM}$.

peaks at $605 \mathrm{~nm}$ and $618 \mathrm{~nm}$, respectively. For the films, the peaks shift to $616 \mathrm{~nm}$ and $632 \mathrm{~nm}$, respectively. The optical bandgaps $\left(E_{\mathrm{g}}^{\mathrm{opt}}\right)$ for $\mathrm{PThBDTP}_{i}$ and $\mathrm{PSeBDTP}_{i}$ are $1.88 \mathrm{eV}$ and $1.85 \mathrm{eV}$, respectively. The smaller bandgap of $\mathrm{PSeBDTP}_{i}$ results from the reduced aromaticity of selenophene. ${ }^{9}$ The HOMO and LUMO energy levels for $\mathrm{PThBDTP}_{i}$ and $\mathrm{PSeBDTP}_{i}$ were calculated from the onset potentials of oxidation $\left(E_{\mathrm{ox}}^{\mathrm{on}}\right)$ and reduction $\left(E_{\mathrm{red}}^{\mathrm{on}}\right)$, respectively (Fig. S9†). ${ }^{10}$ PThBDTP $_{i}$ and PSeBDTP $_{i}$ exhibit deep HOMO levels of $-5.47 \mathrm{eV}$ and $-5.44 \mathrm{eV}$, respectively, and similar LUMO levels of $-3.00 \mathrm{eV}$ and $-2.99 \mathrm{eV}$, respectively. Deep HOMO leads to high $V_{\mathrm{oc}}$ for solar cells. ${ }^{11}$ The energy level diagram for $\mathrm{PThBDTP}_{i}, \mathrm{PSeBDTP}_{i}$ and $\mathrm{PC}_{71} \mathrm{BM}$ is presented in Fig. 3 .

The photovoltaic performance for $\operatorname{PThBDTP}_{i}$ and $\operatorname{PSeBDTP}_{i}$ was evaluated by studying the inverted solar cells with a structure of $\mathrm{ITO} / \mathrm{ZnO} /$ polymer: $\mathrm{PC}_{71} \mathrm{BM} / \mathrm{MoO}_{3} / \mathrm{Ag} .{ }^{12}$ The $J-V$ curves and external quantum efficiency (EQE) spectra for the solar cells are shown in Fig. 4. The performance data are listed in Table 2. A mixed solvent of chloroform : chlorobenzene $(3: 2)$ was used to dissolve PThBDTP $: \mathrm{PC}_{71} \mathrm{BM}$ blend. The best $\mathrm{PThBDTP}_{i}: \mathrm{PC}_{71} \mathrm{BM}$ cells gave a PCE of $8.11 \%$, with a $V_{\text {oc }}$ of $0.95 \mathrm{~V}$, a $J_{\mathrm{sc}}$ of $12.13 \mathrm{~mA}$ $\mathrm{cm}^{-2}$ and a FF of $70.5 \%$. These cells have a D/A ratio of $1: 2(\mathrm{w} / \mathrm{w})$, an active layer thickness of $92 \mathrm{~nm}$ and $0.5 \%$ (v/v) 1,8-diiodooctane (DIO) as the additive (Tables S1-S3†). PSeBDTP ${ }_{i}$ : PC $_{71} \mathrm{BM}$ cells were made by using chlorobenzene as the solvent and the best cells gave a PCE of $6.50 \%$, with a $V_{\text {oc }}$ of $0.91 \mathrm{~V}$, a $J_{\text {sc }}$ of $10.32 \mathrm{~mA} \mathrm{~cm} \mathrm{~cm}^{-2}$ and a $\mathrm{FF}$ of $69.6 \%$. These cells have a D/A ratio of $1: 2(\mathrm{w} / \mathrm{w})$, an active layer thickness of $104 \mathrm{~nm}$ and $1 \%(\mathrm{v} / \mathrm{v})$ DIO as the additive (Tables S4-S6†). Compared with PSeBDTP $i$ cells, PThBDTP $_{i}$ cells gave higher $V_{\text {oc }}$ because of the deeper HOMO level of PThBDTP . $_{i}$ $\operatorname{PThBDTP}_{i}$ cells produce a higher $J_{\text {sc }}$ than $\operatorname{PSeBDTP}_{i}$ cells, and the

Table 1 Optical and electrochemical data for the polymers

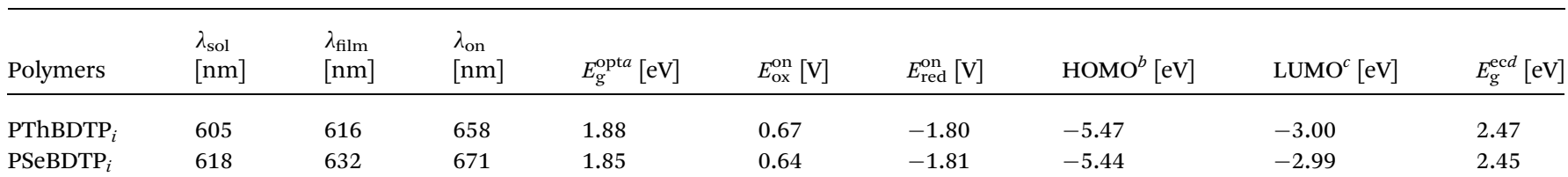

${ }^{a} E_{\mathrm{g}}^{\mathrm{opt}}=1240 / \lambda_{\mathrm{on}} \cdot{ }^{b} \mathrm{HOMO}=-\left(E_{\mathrm{ox}}^{\mathrm{on}}+4.8\right) \cdot{ }^{c}$ LUMO $=-\left(E_{\mathrm{red}}^{\mathrm{on}}+4.8\right) \cdot{ }^{d} E_{\mathrm{g}}^{\mathrm{ec}}=$ LUMO - HOMO. 
(a)

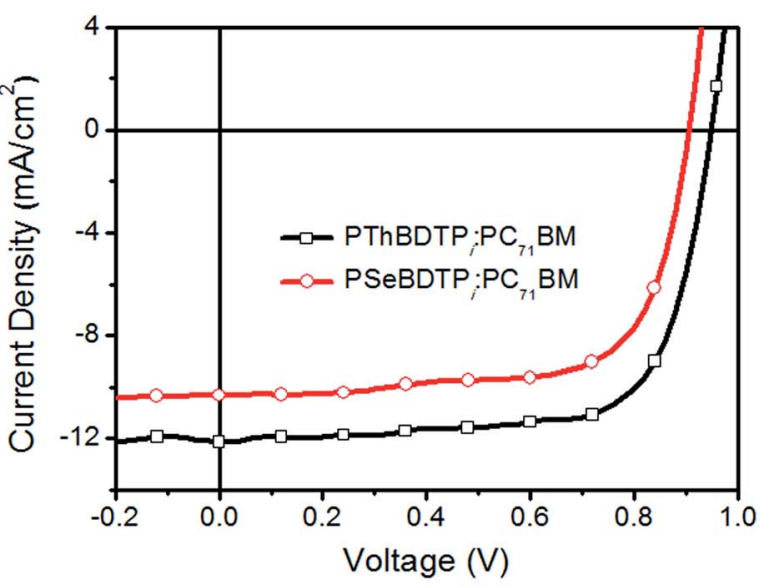

(b)

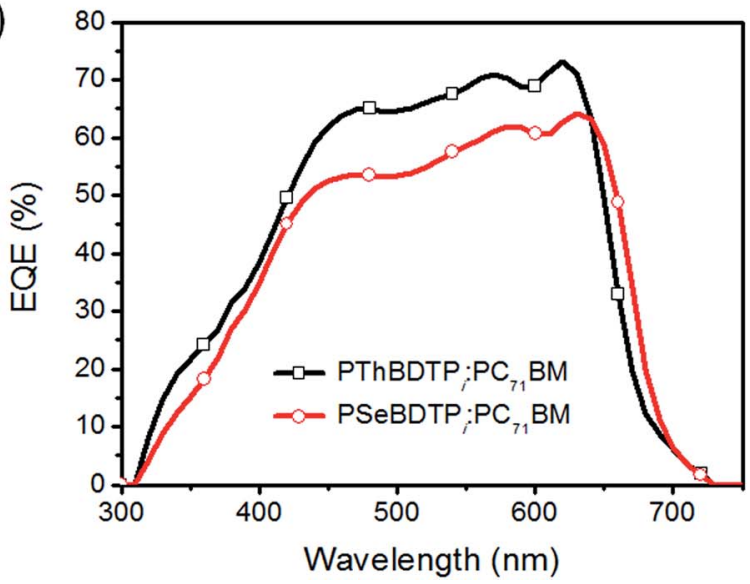

Fig. $4 J-V$ curves (a) and EQE spectra (b) for polymer:PC ${ }_{71} B M$ solar cells.

higher EQE of PThBDTP $i$ cells at 310-640 nm also confirms this. The higher $J_{\mathrm{sc}}$ might result from better charge transporting capability of $\mathrm{PThBDTP}_{i}$. According to space charge limited current (SCLC) measurements, the hole mobilities for PThBDTP $i$ and $\operatorname{PSeBDTP}_{i}$ are $2.60 \times 10^{-4} \mathrm{~cm}^{2} \mathrm{~V}^{-1} \mathrm{~s}^{-1}$ and $1.70 \times 10^{-4} \mathrm{~cm}^{2} \mathrm{~V}^{-1}$ $\mathrm{s}^{-1}$, respectively (Fig. S10 $\dagger$ ). The XRD pattern for PThBDTP $_{i}$ film presents a stronger (010) peak, which corresponds to a $\pi-\pi$ stacking distance of $3.60 \AA$, while PSeBDTP $_{i}$ possesses a $\pi-\pi$ stacking distance of $3.78 \AA$ (Fig. 5). The smaller $\pi-\pi$ stacking $d$ spacing for PThBDTP $_{i}$ might be due to the smaller volume of sulfur atom. The smaller $\pi-\pi$ stacking $d$-spacing favors hole transport. This could explain the higher hole mobility of PThBDTP $_{i}$ and also the higher photocurrent from PThBDTP $_{i}$ cells.

Table 2 Performance data for polymer:PC ${ }_{71} \mathrm{BM}$ solar cells

\begin{tabular}{lllll}
\hline Polymer & $V_{\text {oc }}[\mathrm{V}]$ & $J_{\text {sc }}\left[\mathrm{mA} \mathrm{cm}^{-2}\right]$ & FF [\%] & PCE [\%] \\
\hline PThBDTP $_{i}$ & 0.95 & $12.13(11.20)^{a}$ & 70.5 & $8.11(7.93)^{b}$ \\
PSeBDTP $_{i}$ & 0.91 & $10.32(10.15)$ & 69.6 & $6.50(6.29)$
\end{tabular}

${ }^{a}$ The data in the parentheses are integrated current density from EQE spectra. ${ }^{b}$ The data in the parentheses are averages for 10 cells.

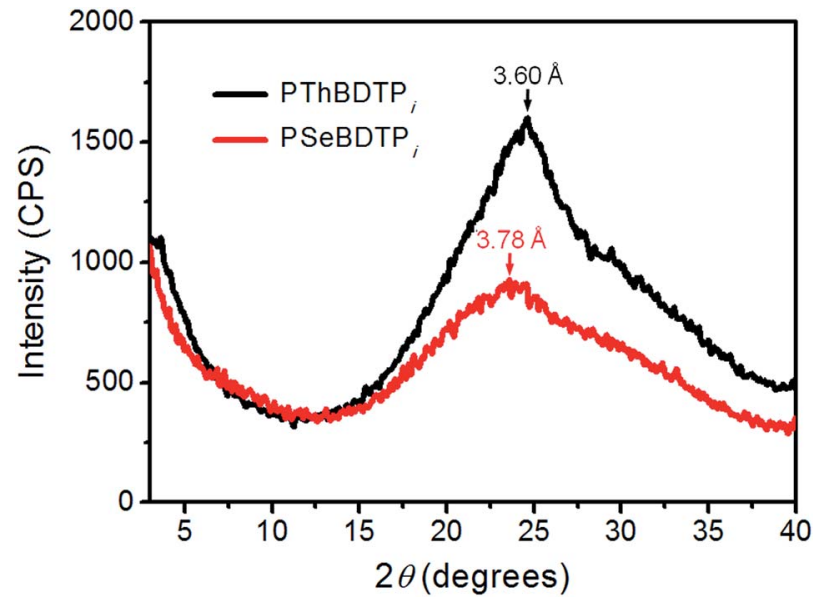

Fig. 5 XRD patterns for PThBDTP $_{i}$ and PSeBDTP $_{i}$ films.

$\mathrm{PThBDTP}_{i}: \mathrm{PC}_{71} \mathrm{BM}$ and $\mathrm{PSeBDTP}_{i}: \mathrm{PC}_{71} \mathrm{BM}$ solar cells without DIO gave low PCEs of $2.55 \%$ and $2.56 \%$, respectively, presenting low $J_{\mathrm{sc}}$ and FF. DIO can effectively dissolve fullerene aggregates and promote fullerene's mixing with polymer to form 3D charge-transport channels. More D/A interfaces could promote exciton dissociation and produce high photocurrent. PThBDTP ${ }_{i}: \mathrm{PC}_{71} \mathrm{BM}$ and PSeBDTP ${ }_{i}: \mathrm{PC}_{71} \mathrm{BM}$ blend films with DIO show fine and clear nano-structures (Fig. S11†), and this ideal morphology is always favourable for improving $J_{\mathrm{sc}}$ and $\mathrm{FF}$ of bulk heterojunction solar cells.

\section{Conclusions}

In summary, an aromatic lactam acceptor unit, $\mathrm{BDTP}_{i}$, was developed. By using this unit, two D-A copolymers, PThBDTP $_{i}$ and PSeBDTP $_{i}$, were synthesized. PThBDTP ${ }_{i}$ PC $_{71} \mathrm{BM}$ solar cells gave a decent PCE of $8.11 \%$. The facile synthesis and good performance of $\mathrm{BDTP}_{i}$ copolymers suggest that $\mathrm{BDTP}_{i}$ is a promising building block for developing high-performance materials for polymer solar cells.

\section{Acknowledgements}

We greatly appreciate National Natural Science Foundation of China (U1401244, 21374025, 21372053, 21572041 and 51503050), State Key Laboratory of Luminescent Materials and Devices (2016-skllmd-05), Youth Association for Promoting Innovation (CAS) and Center for Excellence in Nanoscience (CAS) for financial support. AFM images were taken by Xinjian Geng.

\section{Notes and references}

1 L. Lu, T. Zheng, Q. Wu, A. M. Schneider, D. Zhao and L. Yu, Chem. Rev., 2015, 115, 12666.

2 S. Li, L. Ye, W. Zhao, S. Zhang, S. Mukherjee, H. Ade and J. Hou, Adv. Mater., 2016, 28, 9423.

3 H. Zhou, L. Yang and W. You, Macromolecules, 2012, 45, 607. 
4 J.-S. Wu, S.-W. Cheng, Y.-J. Cheng and C.-S. Hsu, Chem. Soc. Rev., 2015, 44, 1113.

5 A. M. Schneider, L. Lu, E. F. Manley, T. Zheng, V. Sharapov, T. Xu, T. J. Marks, L. X. Chen and L. Yu, Chem. Sci., 2015, 6, 4860.

6 (a) M. Hao, G. Luo, K. Shi, G. Xie, K. Wu, H. Wu, G. Yu, Y. Cao and C. Yang, J. Mater. Chem. A, 2015, 3, 20516; (b) W. Gao, T. Liu, M. Hao, K. Wu, C. Zhang, Y. Sun and C. Yang, Chem. Sci., 2016, 7, 6167.

7 (a) J. Cao, L. Qian, F. Lu, J. Zhang, Y. Feng, X. Qiu, H.-L. Yip and L. Ding, Chem. Commun., 2015, 51, 11830; (b) F. Lu, L. Qian, J. Cao, Y. Feng, B. Du and L. Ding, Polym. Chem., 2015, 6, 7373; (c) K. Zhang, K. Gao, R. Xia, Z. Wu, C. Sun, J. Cao, L. Qian, W. Li, S. Liu, F. Huang, X. Peng, L. Ding, H.-L. Yip and Y. Cao, Adv. Mater., 2016, 28, 4817; (d) X. Du,
O. Lytken, M. S. Killian, J. Cao, T. Stubhan, M. Turbiez, P. Schmuki, H.-P. Steinrück, L. Ding, R. H. Fink, N. Li and C. J. Brabec, Adv. Energy Mater., 2016, DOI: 10.1002/ aenm.201601959.

8 H. Hu, K. Jiang, G. Yang, J. Liu, Z. Li, H. Lin, Y. Liu, J. Zhao, J. Zhang, F. Huang, Y. Qu, W. Ma and H. Yan, J. Am. Chem. Soc., 2015, 137, 14149.

9 A. Patra and M. Bendikov, J. Mater. Chem., 2010, 20, 422.

10 Z. Xiao, G. Ye, Y. Liu, S. Chen, Q. Peng, Q. Zuo and L. Ding, Angew. Chem., Int. Ed., 2012, 51, 9038.

11 B. P. Rand, D. P. Burk and S. R. Forrest, Phys. Rev. B: Condens. Matter Mater. Phys., 2007, 75, 115327.

12 Z. Xiao, X. Geng, D. He, X. Jia and L. Ding, Energy Environ. Sci., 2016, 9, 2114. 